\title{
Symbolic Amateurs
}

\section{On the Discourse of Amateurism in Contemporary Media Culture}

\section{CAROLINE HAMILTON}

UNIVERSITY OF MELBOURNE

'If it feels a little bit like we're amateurs, it is because we are. Everyone is an amateur in this business.' ${ }^{1}$ These were the words Julian Assange used to describe the operations of Wikileaks to the New Yorker in 2010, just weeks after the whistleblowing website published secret video footage of a 2007 US army air strike in Iraq that killed a dozen people. The content of the video-known as 'Collateral Murder'and the means by which it was obtained quickly became a source of global controversy. At the time the Pentagon classified Wikileaks as a threat to US national security and sought (unsuccessfully) to prevent more material surfacing by arguing for what they called 'criminal sanctions'. Since then both Assange and Wikileaks have been the subject of continuing questions about the ethics of their actions: the Wikileaks philosophy of radical transparency and freedom of information contrasts starkly with the established protocols for professional journalists, but their actions, in bringing to light footage that traditional media outlets would never have found, have also been praised. 
This tension between the legitimacy associated with professionalism and the discourses of freedom associated with amateur enterprise has long characterised how the public value the work of these two groups. Since the 1990s, however, thanks largely to the rise of the internet, new dynamics between amateurs, professionals and their publics are emerging. In the case of Wikileaks, although the debate is often presented in stark terms as a choice between professional standards and amateur energies it is clear from Assange's language that the situation is altogether more complex. Just what does he mean, for example, when he states, 'everyone is an amateur in this business?' Amateurs are usually understood to be uninterested in the business aspect of their activity. In the case of Wikileaks is it even possible to know to which business Assange is referring? Publishing? Journalism? Whistle blowing? Hacking? Tasks such as hacking or whistle blowing have no paid, professional equivalent-does this mean that anyone who participates in them must necessarily be regarded as an amateur? This essay takes Assange's comments above as a starting point for investigating these questions and the largely positive rhetoric associated with amateur labours.

We are now very familiar with the discourses of digital do-it-yourselfism that suggest anyone can write the next Fifty Shades of Grey or be the next Justin Bieber. Although amateur new media producers are sometimes criticised for their lack of quality or failure to adhere to particular standards, their efforts have also been interpreted as advancing the cause of democratising media. ${ }^{2}$ As such, amateur participation in professional industries is today routinely positioned as, if not unequivocally 'good', then at least an essentially positive development. When Time magazine devoted a 2006 cover story to the millions of everyday people 'working for nothing and beating the pros at their own game' amateur activities were given high profile endorsement. For their special 'Person of the Year' issue Time flatteringly announced 'You' as the winner. ${ }^{3}$ The article's highly positive language presented amateurs as empowered, independent entrepreneurs ('beating the pros at their own game'), but failed to address why working at the level of professional might also involve some inequalities (such as 'working for nothing'). The issue of amateur labour and inequality in the media industries, while significant, is well covered elsewhere. ${ }^{4}$ Here, I want instead to draw attention to the degree to which 
the amateur, once positioned on the fringes of our culture, now occupies a role much closer to the centre.

\section{-WHO IS AN AMATEUR?}

Before continuing, the very variable parameters of the term 'amateur' need to be explored. Coming from French via Latin, amateur (meaning 'a lover of') was first used in English toward the end of the eighteenth century to describe an individual with a passionate interest in a subject or an activity. The industrial revolution was in full swing by this time and it didn't take long for amateurs to become associated in the minds of the public with the dabbling and dilettantism common to gentlemen of leisure-those men who were financially independent and took on work only in order to portray occupation (such as investor, speculator, adventurer, gambler and so on). This association had two important consequences: it resulted in a downgrading of the knowledge many amateurs possessed to mere fancy or trifling entertainment and it helped formalise the association between amateur activity and financial disinterest. Webster's Dictionary, for example, defines an amateur as 'one that engages in a particular pursuit, study, or science as a pastime rather than as a professional'. This definition demonstrates how the role has been conceived of as functionally dependent on its opposite. Where professionals are understood as needing to be financially compensated for devoting most of their time to an activity, amateurs take on the task in their spare time, content to accept no financial reward.

However commonplace such an understanding of the amateur might be it contains remarkable contradictions and oversights. Although defined in one sense as a devotee who loves a particular activity, in another, 'amateur' connotes superficial, uncommitted participation. Likewise, although devoted, amateurs are also described as inexperienced and unskilled, qualities that don't gel with empirical evidence that suggests anyone devoting time to an activity will develop competency. 5 Trying to define the amateur in relation to the professional can also be misleading since professionals often volunteer their services and amateurs sometimes get paid for their efforts. Making distinctions between the two groups on the basis of time and money also wrongly draws a correlation between 'loving your work' and being uninterested in money, implying that amateurs always draw 
satisfaction from their pastimes while professionals necessarily dislike their work and need financial compensation as inducement.

Trying to define the amateur by taking the professional as a counterpoint is also unproductive from the perspective of the new forms and modes of work that have emerged in the last twenty years. Many work roles (especially in the media industries) now deliberately avoid classification or refuse official forms of consecration or authorisation: the reality-TV celebrity, the social media user, the blogger, the citizen journalist, the hacker, and the media intern are all roles performed somewhere between the lines of paid/unpaid, professional/amateur, authorised/unofficial. These liminal roles (and, increasingly, the liminal spaces where they are performed) are complemented by the equally unofficial online activity known as 'co-creation'. Used to describe the phenomenon of 'nonprofessional audiences participating in the interactive process of making and circulating media content and experiences using the tools and platforms provided by technology companies, "co-creation" unites amateurs and professionals within the field of a single digital economy in which finance and other alternative forms of capital operate and interchange'. ${ }^{6}$ Until very recently one way to understand the work of the amateur had been to note that as a group they have been protected from the alienation and expropriation associated with capitalism because they labour for 'the love of it'. However, as recent scholarship in the fields of sociology and political economy has demonstrated, the digital economy provides exemplary evidence that the potential exists for capitalism to extract financial value from these emotional investments. ${ }^{7}$ Thus, amateurs are as likely as their professional counterparts to experience the exploitation of their labour. On the flipside of this scenario is the proposition that amateurs, hitherto presumed to be professionally disinterested, actually share much in common with their paid counterparts when it comes to professional values, standards and reputation. ${ }^{8}$

This complex situation is not aided by the fact that increasingly the word is applied to more and more groups of people. Audiences, consumers, users, critics and more are all described today under the mantle of amateur, or its new variants- the pro-am, the produser, or the prosumer. ${ }^{9}$ Consider, for example, how many different ways the 'amateur' is figured in contemporary social studies: for social scientists concerned with labour exploitation the emphasis falls on amateurs as unpaid 
contributors to the information and cultural economies; ${ }^{10}$ for critics of the digital cultures that have sprung up across the web the word connotes the unprofessional standards of the unqualified masses; ${ }^{11}$ for media gurus and theorists like Henry Jenkins, Lawrence Lessig and Wired magazine's Chris Anderson, the figure of the amateur personifies the freedom and democracy enabled by open connections. ${ }^{12}$ Used as it is in an ad-hoc manner, the term 'amateur' is now also synonymous with ad-hoc. How then are we to understand today's amateur workers and how do we take account of their value?

\section{-SYMBOLIC AMATEURS}

On the basis of empirical evidence alone, toppling governments and dealing in topsecret military files is not the sort of thing the average person does in their downtime away from the office or after the kids have been put to bed. Assange's version of amateur pursuit involves a field of experience quite distinct from those of the benign enthusiast: Wikileaks have published everything from the operating manuals of the Guantanamo Bay detention camp to the tax records of the movie action-hero Wesley Snipes; they have collaborated with major global media organisations like the Guardian, the New York Times and the Washington Post; Assange can claim the support and friendship of influential names in the media industry along with legal representation by a suite of the world's top lawyers specialising in human rights and international law. ${ }^{13}$ His is a very particular kind of amateurism. The contention that an organisation with the skills, means and impact of Wikileaks is amateur suggests that something has fundamentally shifted in social expectations around amateurs and the kinds of work that they do.

Indeed, Assange's statement is just one example of a wider trend in digital media culture. Consider Google's eagerness to remind users that their billion-dollar business began life as just the pet project of tech students with a motto befitting commercial naïfs: 'don't be evil'. Or Facebook CEO Mark Zuckerberg's initial public offering (IPO) letter to investors that counterintuitively managed to sell shares in a multibillion dollar company on the basis that it was 'not originally created to be a company'.14 The same logic also underpins the success of many reality TV programs, such as Dancing with the Stars and Celebrity Apprentice, which involve the conceit of having recognised professionals perform as amateurs in order to stabilise their 
careers as celebrities. These examples demonstrate one of the increasingly common phenomena in the present media landscape, something that might be best described as symbolic amateurism-that is, adopting the pose of the amateur even while inhabiting the sphere of the professional.

\section{-SELF-CONSCIOUS WORKERS}

The resurgence of discourses in the media relating to the work and culture of the amateur is understood to have arisen with the rapid spread of digital networks since the turn of the century. As far back as 1977, however, the sociologist Robert A. Stebbins noted a growth in occupations (in entertainment, sports, the arts) where what is now work was once purely play. Accompanying this, Stebbins noted, was a surprising development: amateurs, hitherto unconcerned by the performances of their professional counterparts, were now more motivated to emulate them. This he attributed to the 'mass availability of professional performances' in everyday life; in other words the celebration of professionalism in the expanding communications culture was driving amateurs to do more to bring themselves closer to this level. As Stebbins explains: 'As professionalization spreads from one occupation to another, what was once considered play activity in some of these spheres is evolving quietly, inevitably, and unnoticeably into a new form, which is best named modern amateurism.' 15 To Stebbins, modern amateurism reflects a strong desire for recognition, a willingness to turn play into 'obligation, seriousness, and commitment', as participants seek to meet professional standards, effectively imitating the performance of professionals. ${ }^{16}$ Essentially, he noted that an expanding communications culture was making amateurs more aware of the nature of professional standards and, in sensing their distance from these standards and their limited access to professional tools, amateurs were driven to do more to bring themselves closer to their professional counterparts with the aim of achieving some mark of success. Stebbins does not go on to explain the reasons behind this newfound drive, although it is worth noting that his observations on modern amateurism bear a remarkable relation to those of modern scholars of work culture who provide detailed accounts of how the discourses of globalisation and neoliberalisation have impacted on the personal ethics of workers. ${ }^{17}$ 
Enjoying a popular perception as commercially disinterested and emotionally invested, the figure of the amateur is an especially useful resource for a media industry seeking to improve its public relations. Commonly seen as figures for social good, the amateur's work is 'not generally organised by a logic of monetary incentives,' notes Vasilis Kostakis, 'but is chiefly based on values like sharing, respect, socialization, and recognition.' 18 To talk of amateurs is also to indirectly reference positive social attributes like 'natural' talent and innovation, naivety, informality, honesty and freedom. Because they are not interested in business logic amateurs are regarded as demonstrating a particular situated aesthetics and ethics in their work: it is understood that they draw their creativity and innovation from sources unaffected by the marketplace.

That conceptual link between amateurs and ingenuity has been strengthened over the last twenty years because amateurs have been central to the development and promotion of the World Wide Web. The participation of amateurs was central to the development of the early conception of the web as 'a gift economy for information exchange'19 and, more recently, the celebration of the participatory culture of Web2.0 is supported by a discourse in which empowerment, digital networks and amateurs are united in something of a holy trinity. Thus, the digital media environment and the wider cultural ideologies it has nurtured represent a profound paradigm shift in the way we understand the contribution of nonprofessionals, and their symbolic value to our culture. Understood in this context it makes sense that organisations like Google, Facebook and even Wikileaks wish to harness their enterprises to the concept of amateurism; this discourse allows them to identify their operations with mental and spiritual freedom - the kind of freedom that is associated with independence from the commercial world and attaches an implied ethics to their work.

This appealing rhetoric is undercut by closer investigation of operations in the modern media industries. The growing normalisation of amateur activities in the hitherto 'professionals-only' context has blossomed into a not-so-small scale industry in which the talents, styles, modes and habits of the amateur are not only harnessed by business but also self-consciously reproduced. Here, two examples will serve to demonstrate the problem from the perspective of the amateur and the professional respectively. 
Reality TV programs offer particularly rich terrain for exploring the position of amateurs in the media industry. The figure of the aspirational, enthusiastic amateur generates lucrative drama via the pseudo-professionalisation of pastimes, with shows like Masterchef, Next Top Model and X Factor all relying on amateur labour to produce stars. ${ }^{20}$ These programs also promote a discourse in which amateurs are celebrated for their ability to be regular while also displaying remarkably professional abilities. ${ }^{21}$ However encouraging of individual talents and abilities these shows might be, they also reinforce standard patterns of power and control: they ask their participants to perform at the professional level while still being treated as members of the audience. Furthermore, these programs encourage the display of personal life and personality for the purposes of drama while also having real consequences in terms of professionalisation and success. Amateurs in this position cannot remain 'disinterested' for long. Indeed, these programs give drastic warnings to amateurs whose professional disinterest leads them to aspire beyond their abilities.

As discourses of amateurism have reoriented themselves towards the performance of professionalism, discourses in business have turned to emphasise work as a creative, passionate, self-directed enterprise. Enabled and liberated by the information networks of digital communications, business culture has 'become identified with untrammelled mental and spiritual freedom-a freedom once defined by its independence from the commercial realm'.22 On this topic scholars of sociology of work have noted that in the new economy the discourse of amateurism is pervasive even among paid workers and business professionals. Because amateurism emphasises work as a process of developing self-fulfillment, passion, authenticity and self-actualisation it has proven particularly popular among workers in the creative industries where the expectation of external rewards (such as profit) is low. As Angela McRobbie has acknowledged, 'there is a utopian thread embedded in this wholehearted attempt to make-over the world into something closer to a life of enthusiasm and enjoyment'.23 Thus, work becomes imbued with the features of the Romantic tradition, suffused with positive emotional qualities and the discourse of amateurism is internalised by workers, becoming a strategy for regulating the precarity of their own circumstances in the new economy. ${ }^{24}$ 
The concept-if not the reality-of these modes of work links the highly affective, personal, but often unpaid, labours of amateurs with the skills, expertise and standards of professionals, all in satisfaction of the productive principles of the information economy. Professionals are encouraged to be more like their amateur counterparts and take satisfaction in their lack of job security, while amateurs are encouraged to perfect their skills to the professional standard and be flattered by the attention accorded to them. In each case the only certain outcomes relate to profit margins. Malcolm Gladwell typifies the attitude when he writes in Outliers of a young Bill Gates:

We ... marvel that our world allowed that 13-year-old to become a fabulously successful entrepreneur ... But that's the wrong lesson. Our world only allowed one 13-year-old unlimited access to a time-sharing terminal in 1968. If a million teenagers had been given the same opportunity, how many more Microsofts would we have today?25

The appeal of this story is the feel-good idea that anyone with access might have the potential to be the next Gates but behind this is a broader message about the amateur's ability to generate value for business. Celebrating the potent mix of talent, new technologies and accessibility that enabled the teenaged Gates, Gladwell is silent about the ends to which the young amateur is working. What matters most is that his talent can be harnessed to the industry's business outcomes. Or, more correctly, what matters most is that we never again fail to seize the opportunity to harness more talent to the system. Discussing the twenty-first century's GatesFacebook creator Mark Zuckerberg_Lawrence Lessig goes a step further:

what's important here is that Zuckerberg's genius could be embraced by half-a-billion people within six years of its first being launched, without (and here is the critical bit) asking permission of anyone ... Because the platform of the Internet is open and free, or in the language of the day, because it is a 'neutral network', a billion Mark Zuckerbergs have the opportunity to invent for the platform. ${ }^{26}$

Gladwell urges us to learn from history. Lessig offers an upbeat celebration of the fact that amateur access is no longer a problem: the platform is 'open and free' and no one needs permission. Gladwell wonders, how many more Bill Gates might we have had? Lessig responds with, 'a billion Zuckerbergs'! Although presented as a 
wholly positive development, this vision is far from salutary. Zuckerberg has taken the principle of 'not asking permission' as the foundation of his social media platform with very mixed results. ${ }^{27}$

-FRIENDLY BARBARIANS

In his book Ordinary People and the Media, Graeme Turner identifies a shift taking place across all levels of the media industry: 'the key element of the current environment is that, as audiences lose faith (or interest) in the traditional version of the [media] profession's output, and as increasing numbers express their concern about the undesirable concentration of power in the mainstream media industries, the emerging platforms ... are drawing on the voices of their publics.'28 Turner suggests the public flight to social media, blogs and other online sources, and the perennial interest in new reality television formats and genres is connected to the public unwillingness to continue to respect the media as a professional institution or classification. It would seem in response the media have adopted a position of mutual disrespect. According to Turner, the media industry's professional classes are rescinding their commitments as they divest themselves 'of the responsibilities of being providers of information to their citizenry'. Instead, 'they increasingly see themselves as commercial entities responsible to their shareholders rather than the community or nation ... increasingly invest[ing] in the production of social identities as a means of pump-priming the market for other products'. ${ }^{29}$ One example of this 'pump-priming' includes the adoption of the pose of amateurism.

If amateurs were once leisured gentlemen hoping to portray employment they are now just as likely to be successful professionals hoping to portray casual insouciance, financial disinterest, creative liberation or even, as is the case with Assange's comments, radical rebellion. This situation isn't entirely new; for many years businesses have adopted and imitated their amateur counterparts whether it be in terms of lo-fi aesthetics or grassroots distribution models. But in the current media environment where amateurs are themselves contributors to the industries' outputs and success, the adoption of amateur tactics by professionals has broader implications. Consider for example the words of one of the pre-eminent proponents of symbolic amateurism, Nick Denton, a failed journalist and founder of the successful celebrity gossip website Gawker: 'If you run [an internet start up] out of 
your house, then no one expects anything ... If you have an office, people want stuff. They want cell phones, lunch breaks, beer on Fridays.' 30 As Denton indicates, for businesses that present the appearance of being amateur there is the useful side effect of producing low-expectations and thus low overheads, but the adoption of amateurism goes to the very heart of the new media business model. Denton's success is built on his realisation that the amateur blog format and platform can be made to fit the magazine publishing business model. Gawker relies on ambitious amateur bloggers and interns in the New York media industry to produce salacious gossip posts for which they are paid a flat fee per post with a bonus for breaking particular page-view targets. Denton has made no secret that his sole concern is to yield viewer numbers that can be used to sell advertisements. Writers are given access to their metrics in order to encourage them to produce increasingly outrageous headlines to attract new eyeballs. News the public might deem boring becomes a liability for a writer looking to be paid. Although the mainstream media profiles of Denton present him as a new media Mephistopheles, his 'Gawker model' is popularly feted in internet debates about future directions for sustainable online journalism: low overheads in production, high page-per-views yielding advertising dollars, with journalism an unintended, though welcome, consequence. ${ }^{31}$

The rhetoric of amateur participation presents the possibility of an end to cultural gatekeeping and the beginning of a new, amateur (em)powered media participation. As Mark Andrejevic explains, the underlying 'promise of the interactive digital revolution' has been presented as offering the possibility of ending consumer alienation from the means of production and re-enchanting the world through the return of embodied participation in media forms. ${ }^{32}$ In this environment symbolic amateurism has proved extremely useful for media professionals by allowing them to identify with values relating to the social and political freedom of ordinary citizens while still also taking best advantage of the power their industrial position affords. Again, Denton provides a refreshing matterof-factness on this subject. Asked to explain where he understood Gawker sat on the scale of professional enterprise he replied: 'I think of us as being a little like the friendly barbarians ... We're the barbarians who can actually-probably-be hired to defend your gates.' 33 Denton's description of himself and his workers as friendly barbarians is an acknowledgement of how the media has self-consciously enfolded 
the amateur within this system by providing an appealing offer to take up positions as unofficial gatekeepers for the empire.

\section{-CONCLUSION}

The examples provided here illustrate how the discourses of modern day amateurism, informed as they are by prevailing cultural norms relating to work and identity, and the flows of economy and information, are significantly more complicated than simply doing something just 'for the love of it'. Indeed, many of these cases demonstrate how the positive ethical values assumed to inform the work of amateurs in fact serve as rhetorical cover for other modes of more ethically questionable work. Perhaps even in some cases a particularly modern form of work in which the amateur abandons their supposed commercial disinterest to become enfolded into systems of discipline and accumulation.

However, a word of caution is needed. The suggestion that all amateurs are necessarily free and their work 'good' is built upon a fallacy. Amateurs are no more likely to produce work that is unquestionably ethically good than professionals. Amateur labour does not always involve affirmative feelings. Amateurs experience jealousy and competitiveness. They may feel coerced to do certain tasks in order to get ahead in their pursuits and are just as likely as professionals to feel judged (by others or their own high standards). ${ }^{34}$ It also bears recalling that good work doesn't necessarily ensure good outcomes: 'a product may be created to the highest standards available and be dangerous or damaging to large numbers of people. This is true of explosive devices and it may also be true of television programmes. ${ }^{35}$ Or indeed, social networks, search engines or anonymous information sources. Present day attitudes to work and success have an impact on the behaviour of both the would-be professional and the pseudo-amateur. Amateurs schooled in the same work culture as their professional counterparts are just as likely to be uninterested in devoting themselves to common goods. Both groups may enjoy 'good experiences' of their work while remaining ignorant or unconcerned by the social value or impact of aspects of their work and their interests may be self-advancement, or simple personal gratification. Let it not be forgotten that the one-time amateur Mark Zuckerberg celebrated his early success with a business card reading: 'I'm CEOBitch' ${ }^{36}$ 
Caroline Hamilton is McKenzie Research Fellow in Publishing and Communications at the University of Melbourne. In 2013 she is visiting fellow at the School for Advanced Study, University of London. Her research examines the field of independent publishing in the digital era. She is also the author of a book on the publishing success of Dave Eggers called One Man Zeitgeist.

\section{-NOTES}

1 Raffi Khatchadourian, 'No Secrets', New Yorker, 7 June 2010,

<http://www.newyorker.com/reporting/2010/06/07/100607fa_fact_khatchadourian\#ixzz1BvQJgKbx $>$.

2 Perhaps the best-known proponent of the potential for a free digital culture is Lawrence Lessig. See for example, Free Culture: How Big Media Uses Technology and the Law to Lock Down Culture and Control Creativity, Penguin, New York, 2004 and The Future of Ideas: The Fate of the Commons in a Connected World, Knopf Double Day, New York, 2001.

3 Lev Grossman, 'Time's Person of the Year: You', Time.com, 13 December 2006,

<http://www.time.com/time/magazine/article/0,9171,1570810,00.html>.

4 See for example, Mark Andrejevic, 'The Work That Affective Economics Does', Cultural Studies, vol. 25, no. 4-5, 2011, pp. 604-20; José van Dijck, 'Users Like You? Theorising Agency in User-generated Content', Media, Culture \& Society, vol. 31, 2009, pp. 41-58; Angela McRobbie, 'Clubs to Companies: Notes on the Decline of Political Culture in Speeded Up Creative Worlds', Cultural Studies, vol. 16, no. 4, 2002, pp. 516-31; Andrew Ross, No Collar: The Humane Workplace and its Hidden Costs, Temple University Press, Philadelphia, 2004 and Nice Work if You Can Get It: Life and Labour in Precarious Times, NYU Press, New York, 2009; Tiziana Terranova 'Free Labor: Producing Culture for the Digital Economy', Social Text, vol. 18, no. 2, 2000, pp. 33-58.

5 Howard S. Becker, 'Notes on the Concept of Commitment', American Journal of Sociology, vol. 66, July 1960, pp. 32-40.

6 Dmytri Kleiner and Brian Wyrick, 'Infoenclosure 2.0', Mute, 29 January 2007,

<http://www.metamute.org/editorial/articles/infoenclosure-2.0>.

7 Terranova offers a sound analysis of this process, noting how one important consequence of the expanding communications culture has been the understanding of what counts as potentially valuable work. This now includes: 
forms of labor we do not immediately recognize as such: chat, real-life stories, mailing lists, amateur newsletters, and so on. These types of cultural and technical labor are not produced by capitalism in any direct, cause-and-effect fashion; that is, they have not developed simply as an answer to the economic needs of capital. However, they have developed in relation to the expansion of the cultural industries and are part of a process of economic experimentation with the creation of monetary value out of knowledge/culture/affect. (Terranova, p. 38)

8 See John Banks and Mark Deuze, 'Co-creative Labour', International Journal of Cultural Studies, no. 12, 2009, pp. 419-31. As the pair suggest: 'What tends to drive the media professional in their work-peer review, reputation metrics, and a manufactured authenticity-may not necessarily differ all that much from what [amateurs] claim their motivations are' (Banks and Deuze, p. 426).

9 The term 'Pro-Am' was popularised by Charles Leadbeater and Paul Miller in their report The Pro-Am Revolution: How Enthusiasts are Changing our Economy and Society, Demos, London, 2004,

$<$ www.demos.co.uk/files/proamrevolutionfinal.pdf>. 'Produser' was a coinage by media scholar Axel Bruns in his book Blogs, Wikipedia, Second Life, and Beyond: From Production to Produsage, Peter Lang, New York, 2008.

${ }^{10}$ In particular, the nature of paid and unpaid labours in the digital media industry is often framed in terms of the potential for 'self-exploitation.' See for example, Gillian Ursell, 'Television Production: Issues of Exploitation, Commodification and Subjectivity in UK Television Labour Markets', Media, Culture \& Society, vol. 22, no. 6, pp. 805-25.

11 The best known of these critiques is Andrew Keen, The Cult of the Amateur: How Today's Internet is Killing Our Culture, Doubleday, New York, 2007; however, Nicholas Carr's short essay published online also proposes the concept of an encroaching 'hegemony of the amateur'. See Nicholas Carr, 'The Amorality of Web 2.0', Rough Type blog, 3 Oct 2005,

<http://www.roughtype.com/archives/2005/10/the_amorality_o.php>.

12 In addition to Henry Jenkins's Convergence Culture: Where Old and New Media Collide, NYU Press, New York, 2006), Lessig's two books mentioned above and Chris Anderson's Free: The Future of a Radical Price, Hyperion, New York, 2009, see also Yochai Benkler, The Wealth of Networks, Yale University Press, Yale, 2006; Axel Bruns, Blogs, Wikipedia, Second Life, and Beyond: From Production to Produsage, Peter Lang, New York, 2008; Charles Leadbetter, We-Think: Mass Innovation, Not Mass Production, Profile Books, London, 2008 and Clay Shirky, Here Comes Everybody, Allen Lane, New York, 2008.

13 These associations are all detailed in David Kushner, 'Inside Wikileaks' Leak Factory', Mother Jones, 6 April 2010, < http://www.motherjones.com/politics/2010/04/wikileaks-julian-assange-iraq-video>. ${ }^{14}$ Mark Zuckerberg composed a letter to accompany Facebook's initial public offering (IPO) stock market listing. The text of this letter was published online by many sources; see for example 'Facebook IPO: Letter from Mark Zuckerberg', Telegraph, 1 February 2012, 
<http://www.telegraph.co.uk/finance/newsbysector/mediatechnologyandtelecoms/9055830/Facebo ok-IPO-Letter-from-Mark-Zuckerberg.html> .

15 Robert A. Stebbins, 'The Amateur: Two Sociological Definitions', Pacific Sociological Review, vol. 20, no. 4, 1977, pp. 582-606, 582.

16 Ibid., p. 583.

17 For example, Melissa Gregg in Work's Intimacy, Cambridge, Polity, 2011 and David Hesmondhalgh and Sarah Baker in Creative Labour: Media Work in Three Cultural Industries, London, Routledge, 2010, reflect on the ethical and affective dimensions of the new culture of work in the information economy. 18 Vasilis Kostakis 'The Amateur Class, or, The Reserve Army of the Web', Rethinking Marxism: A Journal of Economics, Culture \& Society, vol. 21, no. 3, 2009, pp. 457-61, 458.

${ }^{19}$ Robert Barbrook, 'The High-tech Gift Economy', First Monday, vol. 3, no. 12, $<$ http://www.firstmonday.org/issues/issue3_12/barbrook/>.

${ }^{20}$ For a brief but excellent analysis of the implicit inequalities of current reality television formats see Andrew Ross, 'The Political Economy of Amateurism', Television \& New Media, vol. 10, no. 1, 2009, pp. $135-7$.

${ }^{21}$ Kirsten Seale observes the implications of this process with regard to the Australian version of the television program Masterchef. See 'Masterchef's Amateur Makeovers', Media International Australia, no. 143,2012 , pp. $28-35$.

${ }^{22}$ Lee Siegel, Against the Machine: Being Human in the Age of the Electronic Mob, Spiegel \& Grau, New York, 2008, p. 34.

23 McRobbie, p. 521.

${ }^{24}$ Marion von Osten notes that the exceptional subjects of modernity-artists, musicians, nonconformists and bohemians—now function as business role models. See 'Unpredictable Outcomes: A Reflection after Some Years of Debates on Creativity and Creative Industries', in My Creativity Reader: A Critique of the Creative Industries, ed. Geert Lovink and Ned Rossiter, Institute of Network Cultures, Amsterdam, 2007, 49-58. A similar observation is made by Andrew Ross in both No Collar and Nice Work about how the rhetoric of 'working for the love of it' is used to fashion willing working subjects in the creative industries. In 'Clubs to Companies', McRobbie also develops this theme in her documentation of the working lives of young artists and designers in London. More recently, Melissa Gregg in Work's Intimacy has made a cogent argument regarding the way personal pleasures are used as justification or explanation for routine overwork across a broader sample of employees in the information industries.

${ }^{25}$ Malcolm Gladwell, Outliers, Little Brown \& Company, New York, 2008, p. 313.

${ }^{26}$ Lawrence Lessig, 'Sorkin vs Zuckerberg', New Republic, 1 October 2010,

$<$ http://www.tnr.com/article/books-and-arts/78081/sorkin-zuckerberg-the-socialnetwork?page $=0,1>$. 
${ }^{27}$ Here I am referring in particular to Facebook's reputation for introducing changes to the site's features and privacy policies without first testing or consulting with users. Since the website's earliest beginnings Zuckerberg has operated on the principle that it is better to act first and ask permission (or apologise) later. This tactic appears to have backfired in the case of the current claims against him and other investors involving a 'scam' to cash out shares after the social networking site was floated on the markets in May 2012.

${ }^{28}$ Graeme Tumer, Ordinary People and the Media: The Demotic Turn, Sage, London, 2009, p. 71.

29 Turner, p. 10.

30 This comment is attributed to Denton by a friend and is quoted in a profile of the Gawker Media executive written by Ben McGrath, 'Search and Destroy', New Yorker, 18 October 2010,

<http://www.newyorker.com/reporting/2010/10/18/101018fa_fact_mcgrath>.

${ }^{31}$ Carla Blumencranz, 'Gawker 2002-2007: Pageviews to the People', $n+1,3$ December 2007, <http://nplusonemag.com/gawker-2002-2007>.

32 Mark Andrejevic, Reality TV: The Work of Being Watched, Rowman \& Littlefield, Maryland, 2004, p. 24.

33 Denton quoted in McGrath.

${ }^{34}$ Case studies included in both McRobbie and Ursell demonstrate the complex affective relations among amateur workers in creative roles; Helen Blair, 'You're Only as Good as your Last Job: The Labour Process and Labour Market in the British Film Industry', Work, Employment and Society, vol. 15, no. 1, pp. 149-69.

35 Hesmondhalgh and Baker, p. 36.

${ }^{36}$ Ben Mezrich, The Accidental Billionaires: The Founding of Facebook, Anchor Books, New York, 2010, p. 249. 